\title{
Using flushing rate to investigate spring-neap and spatial variations of gravitational circulation and tidal exchanges in an estuary
}

\author{
D. C. Shaha ${ }^{1}$, Y.-K. Cho ${ }^{1}$, G.-H. Seo ${ }^{1}$, C.-S. Kim ${ }^{1}$, and K. T. Jung ${ }^{2}$ \\ ${ }^{1}$ Department of Oceanography, Chonnam National University, Gwangju 500-757, Korea \\ ${ }^{2}$ Korea Ocean Research and Development Institute, Ansan 426-744, Korea
}

Received: 6 February 2010 - Published in Hydrol. Earth Syst. Sci. Discuss.: 2 March 2010

Revised: 21 July 2010 - Accepted: 26 July 2010 - Published: 5 August 2010

\begin{abstract}
Spring-neap and spatial variations of gravitational circulation and tidal exchanges in the Sumjin River Estuary (SRE) were investigated using the flushing rate. The flushing rate was calculated between multiple estuarine segments and the adjacent bay to examine the spatial variation of two exchanges. The strength of gravitational circulation and tidal exchanges modulated significantly between spring and neap tides, where stratification alternated between well-mixed and highly-stratified conditions over the spring-neap cycle. Tidedriven dispersive flux of salt dominated over gravitational circulation exchange near the mouth during spring tide due to the larger tidal amplitude that caused well-mixed conditions and rapid exchange. In contrast, the central and inner regimes were found to be partially stratified during spring tide due to the reduction in tidal amplitude where both gravitational circulation and tidal exchanges were important in transporting salt. The combined contributions of two fluxes were also found during neap tide along the SRE due to the significant reduction in vertical mixing that accompanied strong stratification. Gravitational circulation exchange almost entirely dominated in transporting salt at the upstream end during spring and neap tides.
\end{abstract}

\section{Introduction}

The net flow of water into and out of estuaries influences the exchanges with the surrounding coastal region, thus playing a role in controlling the estuarine environment by regulating the transport of nutrients, sediments, organisms and pollutants. Therefore, it is essential to understand estuarine hydrodynamic processes, such as tidal exchange and gravitational circulation exchange or some combination of the

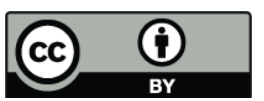

Correspondence to: $\mathrm{Y} . \mathrm{-K}$. Cho

(ykcho@chonnam.ac.kr) two, which transport water and its constituents (Monsen et al., 2002; Ribeiro et al., 2004). The tidal exchange is more or less independent of the river discharge, whereas the gravitational circulation exchange is strongly dependent on the freshwater input in maintaining the longitudinal density gradient that controls an exchange flow, with seaward flow at the surface and landward flow at depth (Officer and Kester, 1991; Dyer, 1997). The competition between tidally induced vertical mixing and river generated buoyancy is the main factor determining the differences in water exchange.

Spring-neap variations in tidal shear stress may result in spring-neap variations in tidally driven mixing, stratification and gravitational circulation (Jay and Smith, 1990; Uncles and Stephens, 1996; Monismith et al., 1996; Ribeiro et al., 2004; Savenije, 2005). Tide-driven shear mechanisms dominate in narrow, shallow estuaries, and strong tidal currents tend to suppress stratification through vigorous mixing, which inhibits gravitational circulation (West and Broyd, 1981; Uncles et al., 1985; Geyer, 1993; Savenije, 2005). However, the weaker turbulence during a neap tide could lead to an acceleration of gravitational circulation (Nunes Vaz et al., 1989; Monismith et al., 1996). Such influence of low mixing at neap tides is noted by Jay and Smith (1990) in the extent of salt intrusion into the Columbia River Estuary.

Gravitational circulation is the most efficient mechanism for flushing river-borne pollutants out to the open sea (Nunes Vaz et al., 1989). In general gravitational circulation increases in strength with increasing river flow (Nguyen et al., 2008), which may cause a depletion of estuarine resident populations by advection from their resident position, particularly larval forms of bottom feeders and deep-water organisms, but also copepods and larval fish (Hough and Naylor, 1991; Jassby et al., 1995; Morgan et al., 1997, Kimmerer et al., 1998, 2002; Monismith et al., 2002). Recently, the spatiotemporal variations on the abundance of the demersal copepod, Pseudodiaptomus sp., in the Sumjin River Estuary (SRE) have been reported (Park et al., 2005). However, there

Published by Copernicus Publications on behalf of the European Geosciences Union. 
has been no information on the physical aspects of the tidal exchange and gravitational circulation exchange for the SRE.

Officer and Kester (1991) use the flushing rate to understand estuarine hydrodynamics and transfer processes that is related to the tidal exchange and gravitational circulation exchange. They calculate single flushing rate for the entire estuarine system. However, Monsen et al. (2002) reported that no single flushing rate for a system is valid for all time periods, locations and constituents, and it does not describe all transport processes. In addition, single flushing rate provides no information about the connections between transport and spatial heterogeneity of non-conservative quantities, such as specific conductivity, temperature and chlorophyll- $a$. As a single flushing rate does not represent the spatial variation of all transport processes, the flushing rate method was applied to multiple segments of the SRE to examine the spatial variability of flushing rate and to estimate gravitational circulation and tidal exchanges.

The main focuses of this study are i) to understand the spatial variation of gravitational circulation exchange and tidal exchange between multiple segments of the SRE and the adjacent bay during spring and neap tides on the basis of the flushing rate and; ii) to suggest the flushing rate as an useful parameter to investigate the relative contribution of the tidal exchange and gravitational circulation exchange in transporting salt up-estuary.

The rest of this paper is organized as follows. The data sources are briefly presented in Sect. 2. The methodology is described in Sect. 3. The results are presented in Sect. 4. A discussion follows in Sect. 5, with the conclusions in Sect. 6.

\section{Study area and data}

The SRE is one of the few natural estuaries on the south coast of Korea. The watershed area, including farmland, is $4897 \mathrm{~km}^{2}$. The Sumjin River discharges into Gwangyang bay. The bay is connected in the south to the coastal ocean (South Sea) and in the east to Jinju bay via the narrow Noryang Channel (Fig. 1). The climate of Korea is characterized by four distinct seasons: spring (March, April, May), summer (June, July, August), autumn (September, October, November) and winter (December, January, February). The mean precipitation is $1418 \mathrm{~mm} \mathrm{a}^{-1}$, based on annual data from 1968 to 2001. Seasonal precipitation and runoff in the Sumjin River basin have decreased in spring and winter, but increased in summer (Bae et al. 2008). The tidal cycle is semi-diurnal, with mean spring and neap ranges of 3.33 and $1.02 \mathrm{~m}$, respectively.

The river discharge data used in this study were from the Songjung gauge station, located about $11 \mathrm{~km}$ upstream from CTD (conductivity-temperature-depth) station $24 \mathrm{op}-$ erated by the Ministry of Construction and Transportation. The maximum monthly median river discharge was highest $\left(370 \mathrm{~m}^{3} \mathrm{~s}^{-1}\right)$ in July 2006 and lowest $\left(11 \mathrm{~m}^{3} \mathrm{~s}^{-1}\right)$

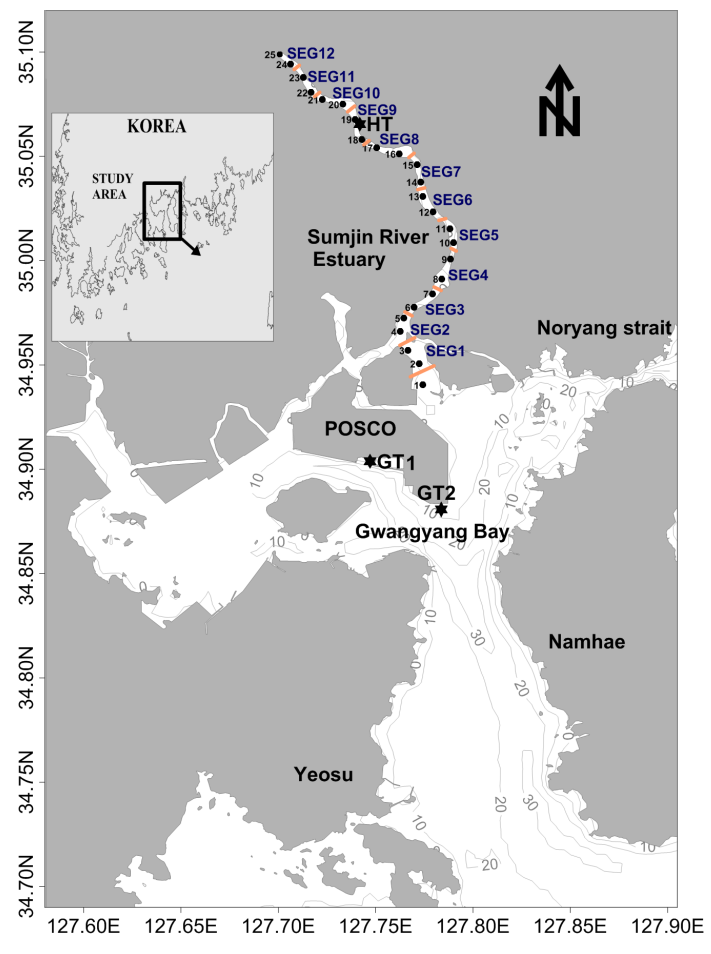

Fig. 1. Map of the study area. The solid circles indicate the CTD stations. The star mark denotes the locations of the Gwangyang (GT1 and GT2) and Hadong (HT) tidal stations.

Table 1. Observed tidal amplitudes for $\mathrm{M}_{2}, \mathrm{~S}_{2}, \mathrm{~K}_{1}$ and $\mathrm{O}_{1}$ at the Gwangyang and Hadong tidal stations.

\begin{tabular}{lllll}
\hline \multirow{2}{*}{ Tidal station } & \multicolumn{4}{c}{ Amplitude (cm) } \\
\cline { 2 - 5 } & $\mathrm{M}_{2}$ & $\mathrm{~S}_{2}$ & $\mathrm{~K}_{1}$ & $\mathrm{O}_{1}$ \\
\hline Gwangyang (GT2) & 109.3 & 46.7 & 18.7 & 14.3 \\
Hadong (HT) & 96.6 & 42.8 & 17.9 & 11.9 \\
\hline
\end{tabular}

in January 2005. Tidal constituents for Gwangyang bay (GT2, Fig. 1) were obtained from the Korean Ocean Research \& Development Institute (http://www.kordi.re.kr/ odmd/harmonic2004/). The $\mathrm{M}_{2}$ tide is the primary tidal constituent at the river mouth. Sea level data for 2005 and 2006 from Hadong tidal (HT) gauge station (http://www.wamis. go.kr/wkw/WL_DUBWLOBS.ASPX) were analyzed using the Task-2000 tidal package developed by the Proudman Oceanographic Laboratory (Bell et al., 1999). The major tidal constituents $\left(\mathrm{M}_{2}, \mathrm{~S}_{2}, \mathrm{~K}_{1}, \mathrm{O}_{1}\right)$ are shown in Table 1. The tidal amplitudes of the $\mathrm{M}_{2}$ and $\mathrm{S}_{2}$ constituents were found to decrease to 12 and $8 \%$ within the estuary at HT, respectively.

Time-series observations of the salinity distribution were conducted over a tidal cycle during spring tide at station 7 on 21-22 July 2005 and on 15-16 June 2006. The longitudinal transects for salinity and temperature were carried out at high water during both spring and neap tides during each season 
from August 2004 to April 2007 using a CTD profiler (Ocean Seven 304 of IDRONAUT Company). A Global Positioning System was used to obtain the locations of the CTD stations (Fig. 1). The nominal distance between the CTD stations was $1 \mathrm{~km}$. The measurements were started from the river mouth one and half hour before high water, and took about one and half hour to complete. On the basis of the stratification parameter, which is the ratio of the difference in salinity between the surface and bottom divided by the depth averaged salinity, well-mixed conditions were found near the mouth of the SRE, with partially-mixed conditions in the central and inner regimes during spring tide. In contrast, strong stratified conditions were found along the SRE during neap tide (Shaha and Cho, 2009).

\section{Methods}

The flushing rate $(F)$ is defined as the rate at which the index quantity is exchanged between multiple estuarine segments and the adjacent sea (Officer and Kester, 1991; Dyer, 1997). Officer and Kester (1991) have calculated single flushing rate near the mouth of Narragansett bay using average bay salinity to understand hydrodynamics and transport processes. A single flushing rate for the whole system does not describe the spatial variation of tidal exchange and gravitational circulation exchange. To calculate the flushing rate between multiple estuarine segments and the adjacent bay, the salt balance equation at steady state condition can be used as follows (Bowden and Gilligan, 1971; Savenije, 1993; Smith and Hollibaugh, 2006; Nguyen et al., 2008).

$R S-A D \frac{\partial S}{\partial x}=0$

where $S$ is the salinity, $A$ is the tidal average cross-sectional area and $R$ represents the river discharge associated with residual flow. $D$ is the dispersion coefficient $\frac{D}{D_{0}}=\left(\frac{S}{S_{0}}\right)^{K}$ where the subscript 0 refers to the situation at $x=0$ and $K$ is the dimensionless coefficient which is larger than zero (Savenije, 1993). The dispersion coefficient $D$ has a large value near the mouth of estuaries, decreasing gradually in the upstream direction to become zero at the toe of salt intrusion curve. This relation adequately describes a combination of density-driven (also called gravitational circulation) and tide-driven dispersion (Savenije, 1993; Nguyen et al., 2008).

The flushing rate $F$ is then given for a single-layer system with multiple segments:

$$
\begin{aligned}
& R S_{\mathrm{mi}}-F_{i}\left(S_{0}-S_{\mathrm{i}}\right)=0 \text { with } F=A D / \Delta x \\
& F_{\mathrm{i}}=\frac{R S_{\mathrm{mi}}}{S_{0}-S_{\mathrm{i}}}
\end{aligned}
$$

$S_{\mathrm{mi}}$ is the salinity of the residual flow assumed at the boundary between the segment of interest and the adjacent source segment (usually the oceanic end member of the estuary).

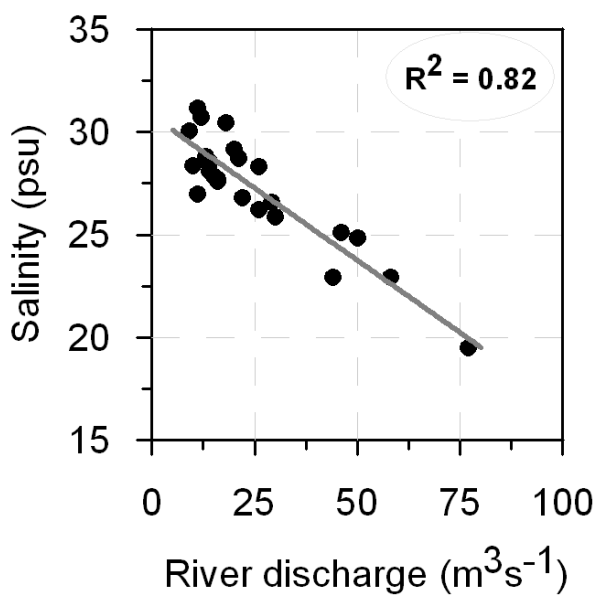

Fig. 2. Salinities observed at $8 \mathrm{~km}$ far from the mouth of the Sumjin River Estuary as a function of river discharge.

Smith and Hollibaugh (2006) suggested that this salinity can be estimated as the average of those two segments, $S_{\mathrm{mi}}=$ $\left(S_{0}+S_{\mathrm{i}}\right) / 2 . S_{0}$ is the salinity of the adjacent bay (oceanic end member of the SRE) and $S_{\mathrm{i}}$ is the segment salinity of interest. The term $\left(S_{0}-S_{\mathrm{i}}\right)$ is the box (segment) model equivalent of the horizontal salinity difference (Smith and Hollibaugh, 2006). If there is a measurable salinity difference between the segment of interest and the adjacent segment $(s)$, Eq. (3) can be solved for exchange flow between many segments and the adjacent bay (Smith and Hollibaugh, 2006). When the salinity difference between the segments becomes small and indistinguishable from 0 , this equation can not be solved for exchange flow because negative $F$ has no physical meaning.

To apply a steady state model in an estuary, it is necessary to examine how quickly the system adjusts to a new situation. If the time required for reaching the system in a new equilibrium is too long, a steady state model can not be used (Savenije, 2005). The residence time of the SRE varied from 3.6 days for the river discharge of $77 \mathrm{~m}^{3} \mathrm{~s}^{-1}$ to 13.5 days for the river discharge of $10 \mathrm{~m}^{3} \mathrm{~s}^{-1}$, with an average of 7.3 and 7.5 days, during spring and neap tide, respectively. In view of the short residence time, SRE can be considered to be near steady state. Salinity versus river discharge relationships can also be used to make a validation of steady state approximations (Regnier et al., 1998). In that case, the solution of salinity versus river discharge should be unique at any position along a steady state estuarine system. Figure 2 shows the yearly evolution of salinity observed at CTD station 8 with various river discharges in the SRE. The approximate homogeneity in salinity was observed for the same river flow which also implies the steady state condition of the SRE.

The quantity $F\left(\mathrm{~L}^{3} \mathrm{~T}^{-1}\right)$ represents the combined effects of the tide-driven exchange and the gravitational circulation exchange, which equals the total longitudinal flux in the Hansen-Rattray estuarine parameter $v$ (Hansen and Rat- 
tray, 1965,1966$). \quad F$ is used to quantify gravitational circulation exchange and tidal exchange. A plot of $F$ versus $R$ illustrates which exchange process is responsible in transporting salt into the system: (1) tidal exchange should be independent of the river discharge, but the gravitational circulation exchange should depend strongly on it (Officer and Kester, 1991; Dyer, 1997). If the tidal exchange is dominant over the gravitational circulation, then the flushing rate $(F)$ should be about constant for all river discharges (Dyer, 1997). This indicates that the total salt transport is caused entirely by tidal exchange and gravitational convection ceases i.e. mixing is dominant over advection. (2) if there were no tidal exchange, a plot of $F$ against $R$ would give a curve with an intercept at zero and increasing values of $F$ for increasing values of $R$ (Dyer, 1997). In that case, the tide-driven dispersive flux of salt is unimportant and upestuary salt transport is entirely dominated by gravitational exchange. Shaha and Cho (2009) found that gravitational circulation was much more effective than tide-driven dispersion in distributing an isohaline of $1 \mathrm{psu}$ at the upstream end of the SRE. (3) If both tidal exchange and gravitational circulation are active, the plot of the flushing rate against the river discharge should have an intercept value $\left(F_{\text {int }}\right)$ at zero river flow, which represents the tidal exchange, and the amounts in excess of the intercept value for various river discharge conditions represent the gravitational circulation exchange $\left(G_{\mathrm{c}}\right)$ (Officer and Kester, 1991; Dyer, 1997). In such condition, the salt transport has contributions from both tide-driven and density-driven processes. Thus, the transport of salt downstream by the river discharge is the sum of the gravitational circulation flux $\left(G_{\mathrm{c}}\right)$ and tide-driven dispersive flux $\left(F_{\mathrm{int}}\right)$. The tide-driven exchanges are dominant over gravitational circulation exchanges if $F_{\mathrm{int}}>G_{\mathrm{c}}$, and the gravitational circulation exchanges over tide-driven exchanges if $F_{\text {int }}<G_{\mathrm{c}}$ for a specific river discharge. The tide-driven dispersive flux of salt exceeds the gravitational flux during a period of decreasing freshwater input (Pilson, 1985; Fram et al., 2007; Nguyen et al., 2008).

The estuarine parameter $v$ is the proportion of the tidedriven fraction $\left(F_{\text {int }}\right)$ to the total upstream salt flux $(F=$ $\left.F_{\text {int }}+G_{\mathrm{c}}\right)$ in an estuary given by Officer and Kester (1991) and Dyer (1997).

$\nu_{\mathrm{i}}=\frac{F_{\text {int }}}{F_{\mathrm{i}}}$

If $v$ approaches 1 , the upstream transport of salt is entirely dominated by tide-driven processes. If $v$ is close to 0 , upestuary salt transport is almost entirely by gravitational circulation. If $0.1<v<0.9$, the system experiences a contribution of both gravitational circulation and tide-driven circulation to the upstream salt transport (Hansen and Rattray, 1966; Valle-Levinson, 2010).

Equation (3) implies that the system is well mixed. However, the SRE shows relatively strong stratification during neap tide and well mixed condition with weak vertical salin- ity gradients during spring tide (Shaha and Cho, 2009). Therefore, the flushing rate has been calculated using Eq. (3) for spring tide considering the system as single layer with multiple segments. In contrast, the flushing rate equation has been modified for two layer circulation during neap tide with multiple segments. For two-layer circulation analytical protocol of Gordon et al. (1996) is followed to calculate the flushing rate.

A steady state in which volume is conserved has volume fluxes

$Q_{\mathrm{si}}=Q_{\mathrm{bi}}+R=F_{\mathrm{i}}$

The oceanic water enters the bottom layer; flows upward $\left(Q_{\mathrm{bi}}\right)$ into the surface layer and out $\left(Q_{\mathrm{si}}=F_{\mathrm{i}}\right)$ to the ocean. The volume of outflow is associated with freshwater inputs.

If salt flux through the mouth is dominated by the exchange flux, then the net salt balance is

$Q_{\mathrm{si}} S_{\mathrm{si}}=Q_{\mathrm{bi}} S_{\mathrm{bi}}$

where $S_{\mathrm{bi}}$ is the bottom salinity and $S_{\mathrm{si}}$ is the surface salinity of each segment. The inflow from the oceanic end member to the segment of interest through boundary $(i=1 \ldots 12)$ reads the following.

$Q_{\mathrm{bi}}=\frac{R S_{\mathrm{si}}}{S_{\mathrm{bi}}-S_{\mathrm{si}}}$

Flushing rate is then given for two-layer system with multiple segments:

$F_{\mathrm{i}}=\frac{R \frac{S_{\mathrm{si}}+S_{\mathrm{si}-1}}{2}}{S_{\mathrm{bi}}-S_{\mathrm{si}}}+R$

Equation (8) can be solved for exchange flow between many segments and the adjacent bay only if there is a salinity difference between the bottom salinity $\left(S_{\mathrm{bi}}\right)$ and the surface salinity $\left(S_{\mathrm{si}}\right)$. As the SRE is stratified during neap tide, the salinity of the upper stratified layer was averaged to obtain $S_{\mathrm{si}}$. In this study, the bottom salinity is considered as $S_{\mathrm{b} 0}\left(=S_{\mathrm{b} 1}=\ldots=S_{\mathrm{b} 10}\right)$. Landward of $18 \mathrm{~km}$ depth average salinity is used to calculate flushing rate considering the system as one layer due to the absent of two layer circulation.

To obtain more accurate estimation of the flushing rate at the boundary between segments, the SRE was divided into twelve segments, with $2 \mathrm{~km}$ in length. The segmentation provides a box model approximation of the longitudinal salinity gradients. The flushing rate was calculated between multiple estuarine segments and the adjacent bay in response to the daily average freshwater input. Two CTD stations were allocated for each segment to obtain average salinity $\left(S_{\mathrm{i}}\right)$ of that segment. The salinity of the seawater entering the SRE via Gwangyang bay varied with time. The CTD station 1 was treated as the seaward boundary for reference salinity of the seawater $\left(S_{\mathrm{b} 0}\right)$ entering in the bottom and $S_{\mathrm{si}}$ of the seawater surface salinity near the mouth. 

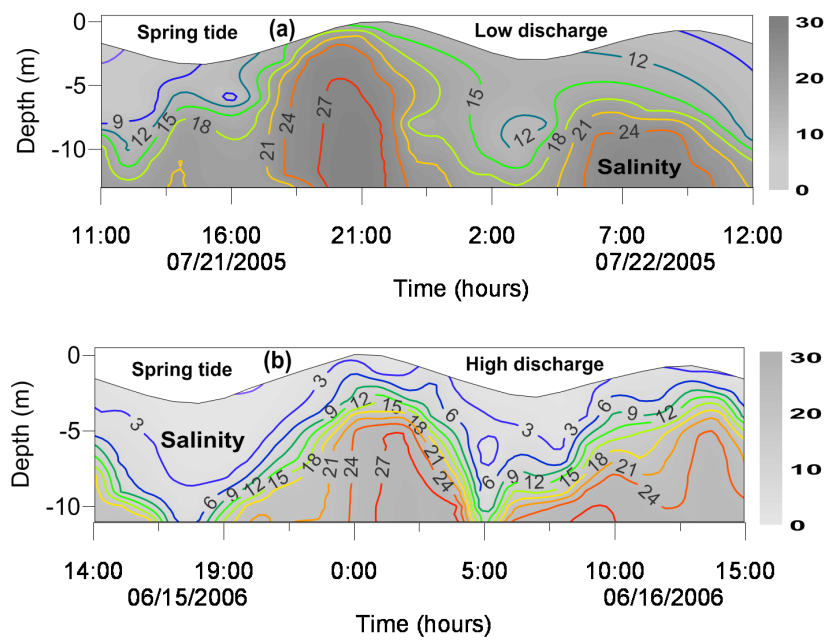

Fig. 3. Time-depth distributions of the salinity profile during spring tide, with low river discharge $\left(28 \mathrm{~m}^{3} \mathrm{~s}^{-1}\right)$ on 21-22 July 2005 (a), and with high river discharge $\left(120 \mathrm{~m}^{3} \mathrm{~s}^{-1}\right)$ on 15-16 June 2006 (b) over a tidal cycle at station 7 .

\section{Results}

\subsection{Diurnal variation of salinity}

A time-series of salinity was observed over a tidal cycle during spring tide at CTD station 7 on 21-22 July 2005 and on 15-16 June 2006. The mean river discharges over the $\mathrm{M}_{2}$ tidal cycle were 28 and $120 \mathrm{~m}^{3} \mathrm{~s}^{-1}$ in 2005 and 2006, respectively. During high tide, a salinity of $27 \mathrm{psu}$ was found at the observation point both in 2005 and 2006 (Fig. 3a-b) and the high tide heights were 3.8 and $3.6 \mathrm{~m}$ in 2005 and 2006, respectively. Comparing two distributions with each other, it appeared that the buoyancy force as a freshwater input was the main differentiating factor. Although the river discharge was 77\% larger in 2006 than that in July 2005, the increased river discharge did not hinder the inflow of $27 \mathrm{psu}$ salt wedge from Gwangyang bay to the observation point but increased the vertical salinity gradient of $50 \%$. The difference in salinity between two subsequent high tides was approximately $3 \mathrm{psu}$. As the high water height differences between two subsequent high tides were $0.71 \mathrm{~m}$ in 2005 and $0.67 \mathrm{~m}$ in 2006, this difference might cause that variation.

\subsection{Longitudinal variation of salinity}

Tide and river discharge are two main forcing factors controlling estuarine circulation (deCastro et al., 2004; Savenije, $2005 ; \mathrm{Ji}, 2008)$. Changes in the tidal currents with the springneap tidal cycle can result in fortnightly modulation of stratification and gravitational circulation (Simpson et al., 1990; Ribeiro et al., 2004). Longitudinal transects of salinity were carried out at high water during both spring and neap tides in each season from August 2004 to April 2007. The vertical
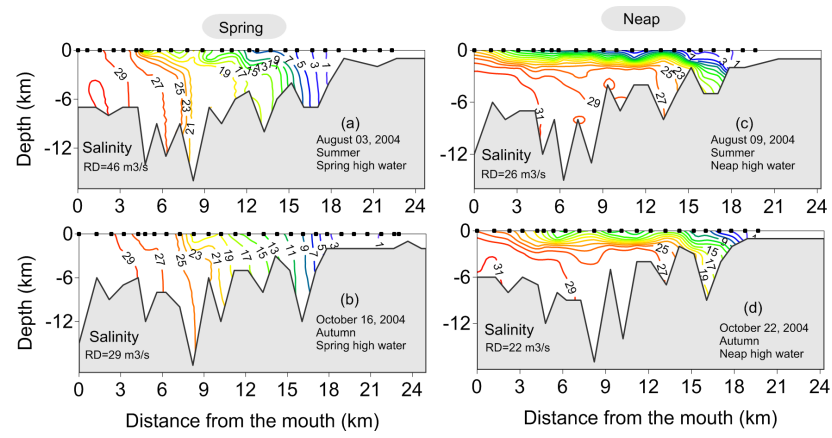

Fig. 4. Salinity distributions for all longitudinal depth surveys of the Sumjin River Estuary at high water during spring (a, b) and neap (c, d) tides during summer and autumn of 2004. The black solid circles indicate the CTD stations.
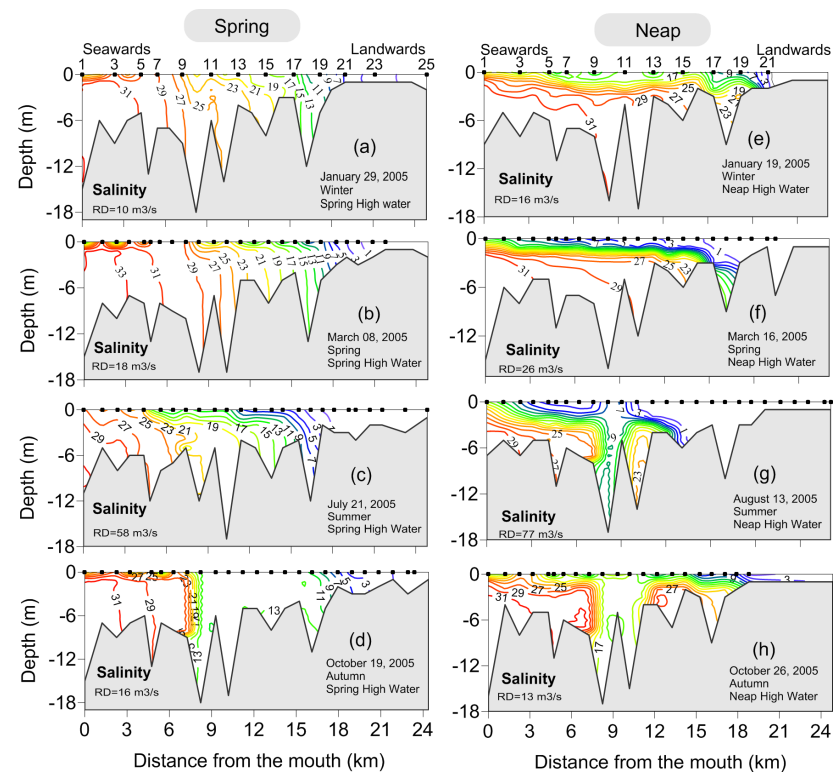

Fig. 5. Salinity distributions for all longitudinal depth surveys of the Sumjin River Estuary at high water during spring (a, b, c, d) and neap $(\mathbf{e}, \mathbf{f}, \mathbf{g}, \mathbf{h})$ tides in each season of 2005 . The black solid circles indicate the CTD stations.

sections showed a relatively well mixed to partially mixed structure during spring tide (Figs. 4 and 5). The highest saline water of 33 psu appeared at the lower portion of the estuary over the entire observation periods during spring, 2005 (Fig. 5b). In addition, an isolated structure of saline water appeared about $9 \mathrm{~km}$ upstream from the mouth (Fig. 5d, g and $\mathrm{h}$ ). This phenomenon may have occurred due to mixing between seawater and freshwater inflow from the tributary (Hwangchon), as the density structure is largely controlled by the freshwater input in the coastal water and the density structure followed that salinity distribution. The vertical sections of salinity $(2006,2007)$ during spring and neap tides have not been shown here owing to their similar structures. 

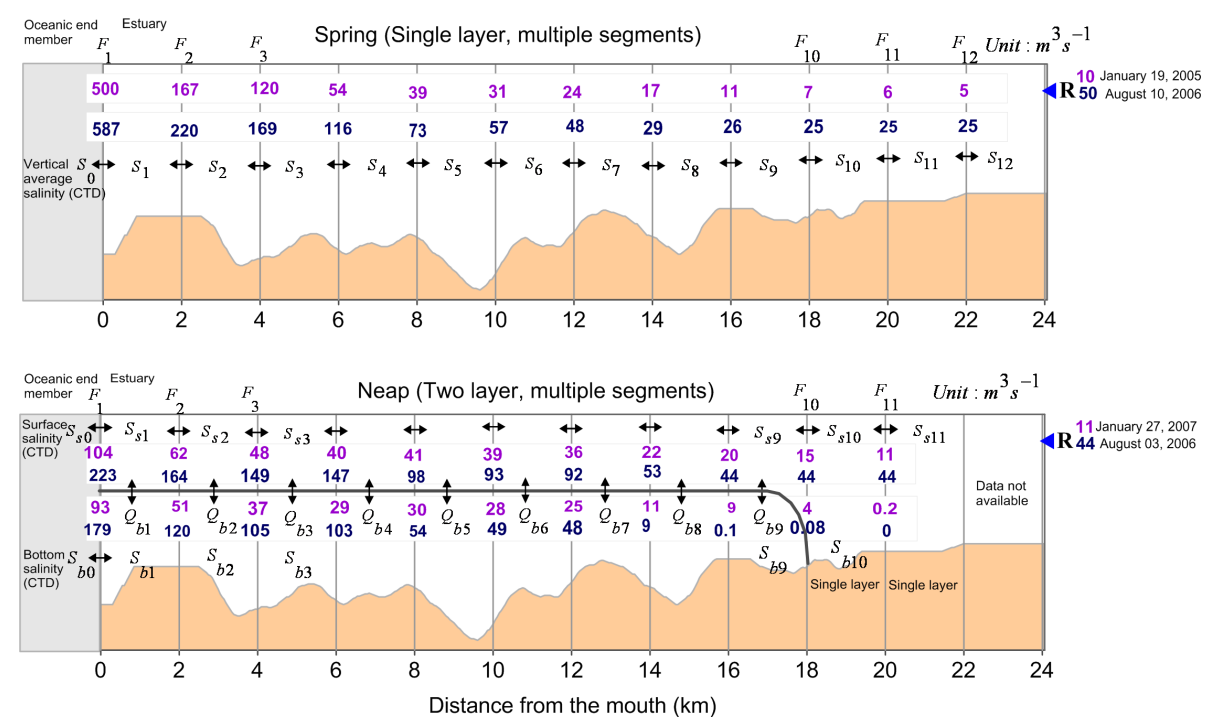

Fig. 6. Schematic diagram illustrating the calculation of flushing rate at the boundary between two adjacent segments for well and partially mixed condition during spring tide (upper) and for stratified condition during neap tide (lower) with low $\left(10\right.$ and $\left.11 \mathrm{~m}^{3} \mathrm{~s}^{-1}\right)$ and high $(50$ and $44 \mathrm{~m}^{3} \mathrm{~s}^{-1}$ ) river discharges $(R)$. In two layer system during neap tide, the outflow $\left(F_{\mathrm{i}}\right)$ from the surface layer to the ocean through boundary is the sum of deep flow volume $\left(Q_{\mathrm{bi}}\right)$ plus river discharge.

Strong stratification appeared during neap tide in all seasons (Figs. 4 and 5). As the tidal amplitude decreased during neap tide, the weakened effect of the bottom friction strengthens the gravitational circulation, causing strong stratification. Strong stratification and gravitational circulation during neap tide was noted by Monismith et al. (1996) in Northern San Francisco bay. On the basis of the stratification parameter, the SRE transitions from partially or wellmixed during spring tide to stratified during neap tide (Shaha and Cho, 2009). In general, the strength of stratification was comparatively increased in summer due to the high river discharge $\left(77 \mathrm{~m}^{3} \mathrm{~s}^{-1}\right.$ ) than other seasons (Fig. $5 \mathrm{~g}$ ).

\subsection{Spring-neap and spatial variations of gravitational circulation exchange and tide-driven exchange}

To investigate the spatial variations in gravitational circulation exchange and tide-driven exchange during spring and neap tides, the flushing rate was calculated at twelve boundaries starting from the oceanic end member to upstream end by dividing the SRE into twelve segments. The schematic diagram (Fig. 6) illustrates the calculation of flushing rate for well and partially mixed condition during spring tide (upper) and for stratified condition during neap tide (lower) with low and high river discharge $(R)$ conditions. At low river discharge condition during spring tide (neap tide), the flushing rate increased by a factor of 100 (9) from the upstream end to the mouth of the SRE. At high river discharge during spring tide (neap), the flushing rate increased by a factor of 23 (5) from the upstream end to the mouth of the SRE. Figure 7 shows the spatial variations of the mean flushing rate during

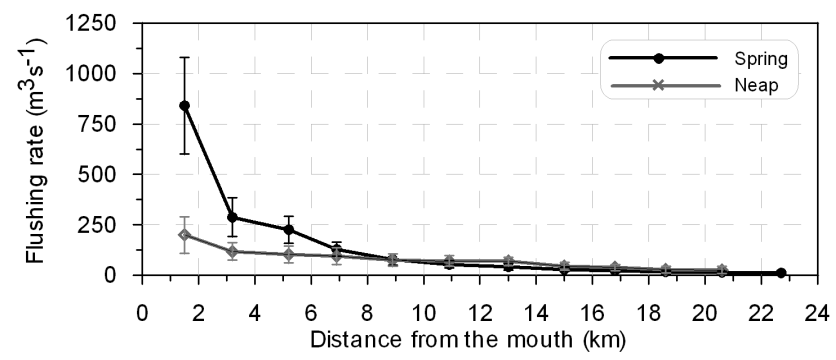

Fig. 7. Spatial variation of the mean flushing rate $\left(\mathrm{m}^{3} \mathrm{~s}^{-1}\right)$ during spring and neap tides.

spring and neap tides. The mean flushing rate was extremely heterogeneous, ranging from 13 to $842 \mathrm{~m}^{3} \mathrm{~s}^{-1}$. The standard deviation became very large at the oceanic end member as the denominator of Eqs. (3) and (8) approached to about zero. The small fluctuation of this denominator yielded very sparse flushing rate near the mouth which caused large scale standard deviation. The flushing rate was approximately four times greater near the mouth during spring tide due to the larger tidal amplitude than during neap tide. The flushing rate varied significantly between spring and neap tides landward of $7 \mathrm{~km}$ from the mouth of the SRE. This length is consistent with the observed median tidal excursion length of $6.8 \mathrm{~km}$ (Shaha and Cho, 2009). The higher the flushing rate, the more efficient the downstream of the SRE is to flush out. Landward of $8 \mathrm{~km}$ the flushing rates were approximately the same during spring and neap tides due to decreasing tidal effects in the central and inner regimes (Table 1). 
Table 2. Volume average salinity $(S)$ for the Sumjin River Estuary, ocean salinity $\left(S_{0}\right)$, and river discharges $(R)$ for various periods of the year along with calculated flushing rate $(F)$ during spring and neap tides.

\begin{tabular}{cccc|cccc}
\hline \multicolumn{4}{c}{ Spring } & \multicolumn{4}{c}{ Neap } \\
\hline$R\left(\mathrm{~m}^{3} \mathrm{~s}^{-1}\right)$ & $S$ & $S_{0}$ & $F\left(\mathrm{~m}^{3} \mathrm{~s}^{-1}\right)$ & $R\left(\mathrm{~m}^{3} \mathrm{~s}^{-1}\right)$ & $S$ & $S_{0}$ & $F\left(\mathrm{~m}^{3} \mathrm{~s}^{-1}\right)$ \\
\hline 46 & 15.42 & 31.46 & 90.20 & 26 & 17.75 & 32.07 & 58.22 \\
29 & 16.92 & 31.16 & 63.48 & 22 & 18.42 & 31.02 & 54.14 \\
10 & 20.27 & 32.43 & 26.67 & 16 & 20.10 & 32.82 & 41.26 \\
18 & 21.17 & 33.57 & 48.75 & 26 & 12.36 & 32.36 & 42.07 \\
58 & 14.59 & 30.46 & 111.32 & 77 & 9.29 & 30.61 & 110.57 \\
16 & 16.27 & 31.59 & 32.98 & 13 & 19.44 & 31.58 & 33.81 \\
20 & 20.92 & 32.55 & 56.00 & 14 & 19.20 & 32.73 & 33.88 \\
11 & 24.45 & 33.51 & 40.69 & 30 & 16.22 & 33.16 & 58.72 \\
50 & 12.45 & 30.00 & 85.47 & 44 & 12.80 & 29.24 & 78.25 \\
9 & 22.20 & 31.83 & 29.75 & 15 & 19.75 & 31.08 & 41.15 \\
12 & 25.88 & 32.94 & 56.03 & 11 & 19.97 & 32.71 & 28.23 \\
21 & 18.87 & 32.95 & 49.14 & 14 & 17.88 & 32.83 & 30.74 \\
\hline
\end{tabular}

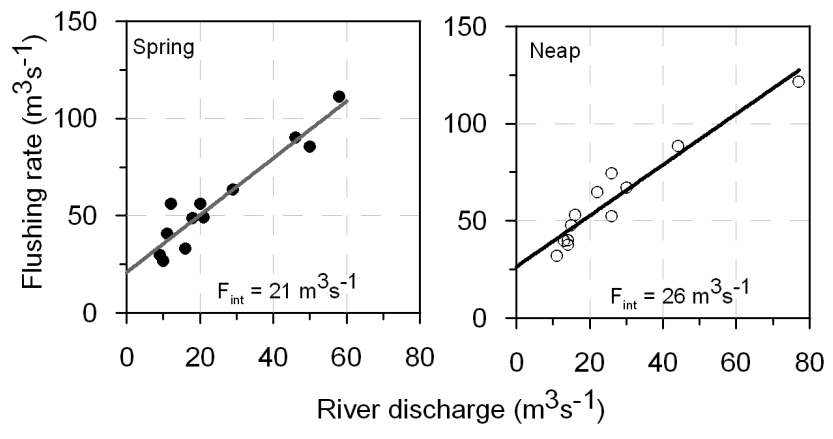

Fig. 8. Plot of the flushing rate $(F)$ calculated for the average salinity of the Sumjin River Estuary against the river discharge $(R)$ during spring and neap tides. The intercept value, $F_{\text {int }}$, denotes the tide-driven exchange. The amounts in excess of $F_{\text {int }}$ for the various river discharges indicate the gravitational circulation exchange $\left(G_{\mathrm{c}}\right)$.

Volume average salinity $(S)$ for the SRE, ocean salinity $\left(S_{0}\right)$, and river discharges $(R)$ for various periods of the year along with calculated flushing rate $(F)$ during spring and neap tides are given in Table 2 . Figure 8 is a plot of flushing rate for the average salinity of the SRE, which is a single flushing rate, versus the river discharge during spring and neap tides. This represented a combined effect of the tide-driven exchange and gravitational circulation exchange in transporting salt upstream. The intercept value $\left(F_{\text {int }}\right)$ provides the tidal exchange whereas the amounts in excess of the intercept value (here expressed by $G_{\mathrm{c}}$ ) for various river discharge conditions give the gravitational circulation exchange. Tide-driven dispersive flux of salt exceeded gravitational circulation flux at river discharge of $<20 \mathrm{~m}^{3} \mathrm{~s}^{-1}$. This combined effect depicts only the general exchange characteristics of the SRE without differentiating spatial variations. Such combined effect was noted by Officer and Kester (1991) for the entire Narragansett bay.
To understand the spatial variations in the tide-driven exchange and gravitational circulation exchange along the SRE during spring tide, the flushing rate for each estuarine segment was plotted against the river discharge (Fig. 9). The tidal exchange was dominant over gravitational circulation exchange near the mouth (SEG1-3) during spring tide where the flushing rate was about constant for all river discharges. The flushing rate data were relatively sparse at the oceanic end member as the small fluctuation of the denominator of Eq. (3) yielded large scale flushing rate. Although the standard deviation was large, the fitting provides a constant value of $F$ indicating tide-driven dispersive flux of salt which was supported by the calculation of potential energy anomaly (see in discussion) and estuarine parameter $v(=1.04)$. Tide-driven dispersive flux dominated over gravitational circulation exchange in transporting salt landward of $7 \mathrm{~km}$ from the mouth of SRE during spring tide due to the larger tidal amplitude of the spring cycle. McCarthy (1993), Savenije (1993, 2005) and Nguyen et al. (2008) reported that the gravitational circulation is weak near the mouth of exponentially varying estuary, and tide-driven exchange is dominant. On the basis of the stratification parameter, well-mixed conditions were also found near the mouth of the SRE during spring tide (Shaha and Cho, 2009), where the large tidal amplitude enhanced the turbulent mixing. Moreover, the tidal dominancy appeared in the observations of the variations in the diurnal salinity taken at CTD station 7 with low $\left(28 \mathrm{~m}^{3} \mathrm{~s}^{-1}\right)$ and high $\left(120 \mathrm{~m}^{3} \mathrm{~s}^{-1}\right)$ river discharges during spring tide, as shown in Fig. 3. In both river discharge cases, the same salinity of 27 psu appeared at CTD station 7 during high tide (Fig. 3a and b). This indicates that the tide was dominant in pushing the salinity of 27 psu from Gwangyang bay to the observation point, where the freshwater input was negligible. 

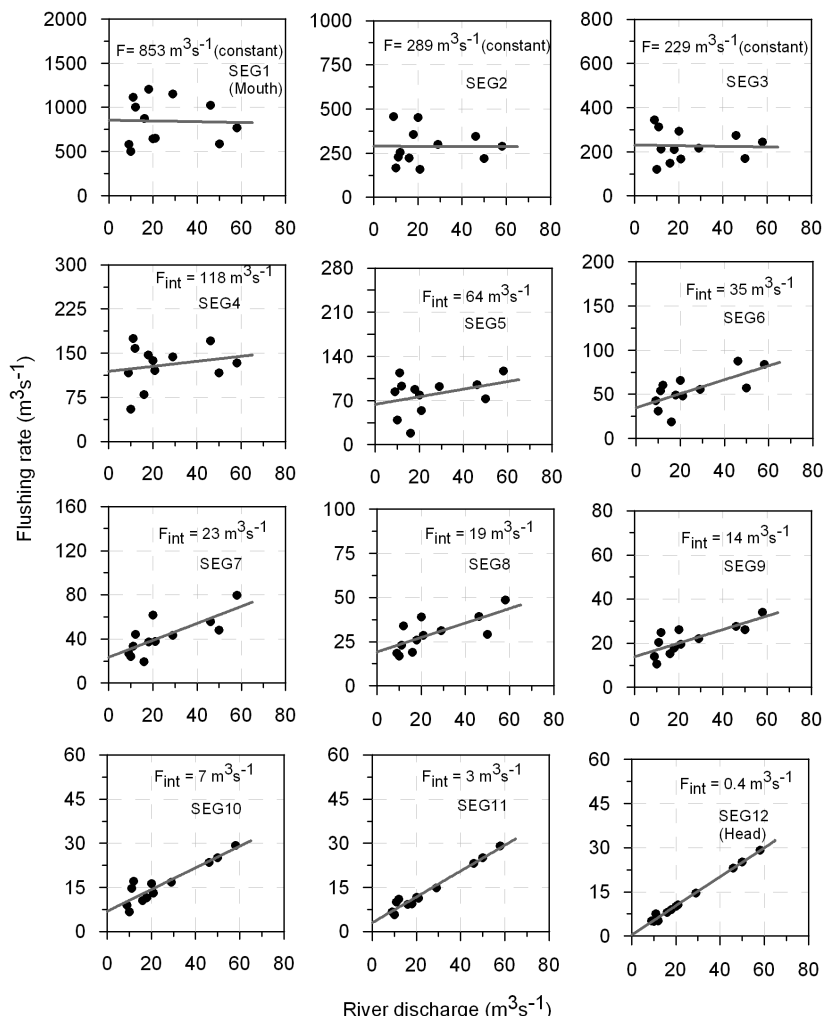

Fig. 9. Plot of the flushing rate $(F)$ against the river discharge $(R)$ for various segments of the Sumjin River Estuary during spring tide. The intercept value, $F_{\text {int }}$, indicates the tidal exchanges. The amounts in excess of the $F_{\text {int }}$ value for various river discharges indicate gravitational circulation exchange (here expressed by $G_{\mathrm{c}}$ ). Gravitational circulation exchanges entirely dominate at the upstream end.

The combined contribution of tidal exchange and gravitational circulation exchange were found in segments 4 to 10 during spring tide (Fig. 9), where the SRE shows partially stratified condition on the basis of the stratification parameter (Shaha and Cho, 2009) and also as a function of potential energy anomaly. Gravitational circulation exchange and tidedriven dispersive flux were differed with the salt content rate of change for various river discharges. Tide-driven dispersive flux of salt dominated at low river discharge $\left(10 \mathrm{~m}^{3} \mathrm{~s}^{-1}\right)$ condition in these segments. Fram et al. (2007) found that tide-driven dispersive flux of salt exceeds gravitational circulation during a period of decreasing river discharge. However, gravitational circulation exchange exceeded tide-driven dispersive flux at river discharge of $50 \mathrm{~m}^{3} \mathrm{~s}^{-1}$ in the upper segments (SEG6-11). As the $\mathrm{M}_{2}$ tidal amplitude decreased by $12 \%$ within the estuary relative to the mouth (Table 1 ), the consequent reduction in the vertical mixing and increasing river discharge enhanced gravitational circulation by increasing potential energy on the water column. Due to the decrease in tidal amplitude, the gravitational circulation has intensified in Ariake bay (Yanagi and Abe, 2005). As a con-
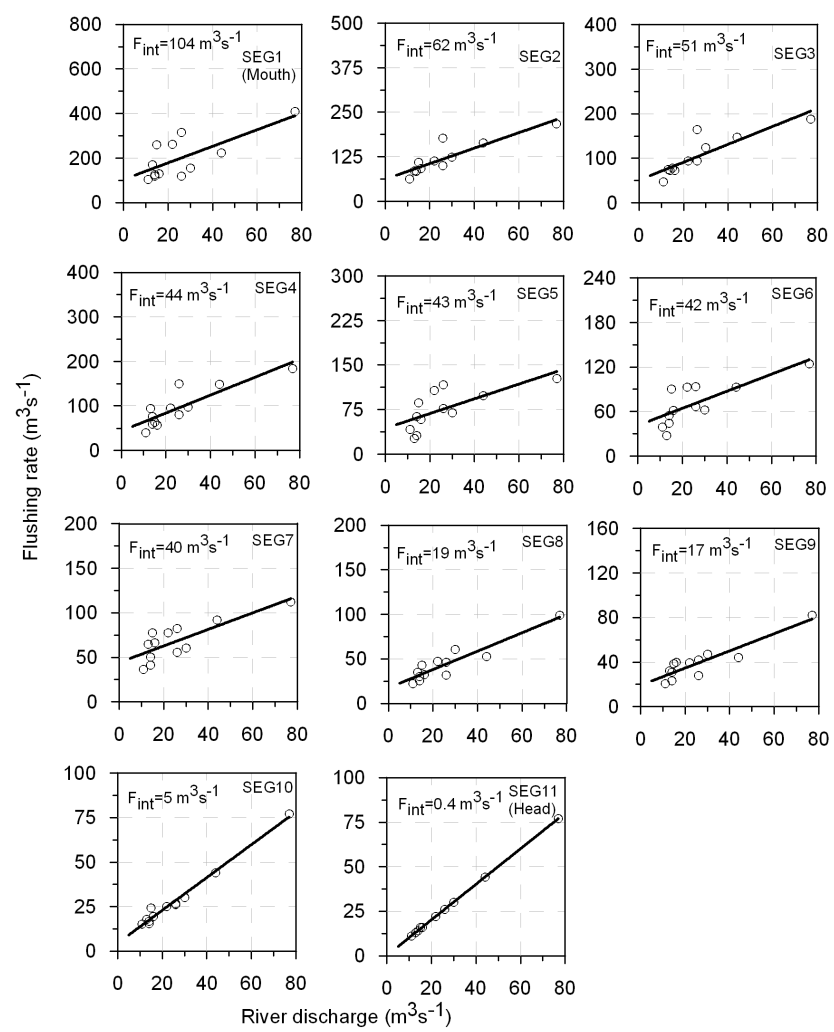

Fig. 10. Plot of the flushing rate $(F)$ against the river discharge $(R)$ for various segments of the Sumjin River Estuary during neap tide. The intercept value, $F_{\text {int }}$, indicates the tidal exchanges. The amounts in excess of the $F_{\text {int }}$ value for various river discharges indicate gravitational circulation exchange (here expressed by $G_{\mathrm{C}}$ ). Gravitational circulation exchanges entirely dominate at the upstream end.

sequence, the combined contribution of tidal exchange and gravitational circulation exchange were important in transporting salt landward of $8 \mathrm{~km}$. In contrast, gravitational flux was much more effective in transporting salt to segment 11 and 12 during spring tide, which is governed by the river flow. Savenije (1993) and Nguyen et al. (2008) also found that gravitational circulation exchange is dominant in the upstream part.

The combined contribution of tidal exchange and gravitational circulation exchange were also found in transporting salt from segment 1 to 10 during neap tide (Fig. 10). The weaker turbulence during neap tide accelerated the gravitational circulation exchange along the SRE. As a consequence, both tidal exchange and gravitational circulation exchange were important in transporting salt upstream. Tidedriven dispersive flux of salt was also dominant over gravitational flux during neap tide at river discharge of $10 \mathrm{~m}^{3} \mathrm{~s}^{-1}$. Gravitational circulation exchange was dominant over tidal exchange along the SRE during neap tide at river discharge of $50 \mathrm{~m}^{3} \mathrm{~s}^{-1}$. This indicates that strong gravitational circulation exchange was strongly linked to both the stratification 


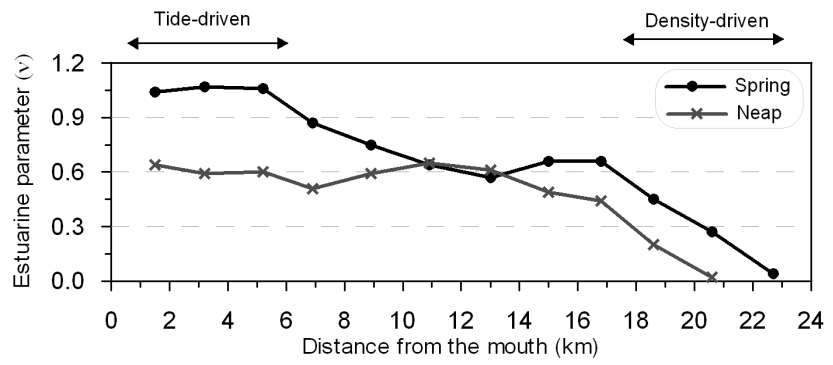

Fig. 11. Spatial variation of median estuarine parameter $(v)$ during spring and neap tides along the Sumjin River Estuary. For $v \sim 1$, upestuary transport of salt entirely by tide-driven mixing. For $v \sim 0$, up-estuary salt transport almost entirely by gravitational circulation. For $0.1<v<0.9$, both gravitational circulation and tide-driven circulation contribute to transporting salt up-estuary.

and the tide (neap). Strong stratified conditions were found during neap tide along the SRE as a function of the stratification parameter (Shaha and Cho, 2009) and the potential energy anomaly in the water column. Pulsing of stratification and gravitational circulation is easily understood in terms of the significant reduction in vertical mixing during neap tide due to the weakened effect of the bottom friction (Monismith et al., 1996). Gravitational circulation exchange was entirely dominant in transporting salt to segment 11 during neap tide, which is governed by the river flow.

The estuarine parameter $v$ (Hansen-Rattray parameter), as determined from Eq. (4), obviously illustrates which exchange process is responsible in transporting salt up-estuary. On the basis of the estuarine parameter $v$ (Fig. 11), the tidedriven dispersion was almost constant landward of $6 \mathrm{~km}$ from the mouth of the SRE during spring tide where $v>0.9$. This length is consistent with the observed median tidal excursion length of $6.8 \mathrm{~km}$ (Shaha and Cho, 2009) where gravitational circulation ceased and the upstream transport of salt was entirely dominated by tide-driven dispersion (Fig. 9, SEG1-3). From 7 to $19 \mathrm{~km}$ both gravitational circulation and tide-driven dispersive fluxes had contributions in transporting salt during spring tide (Fig. 9, SEG4-11) where $0.1<$ $v<0.9$. Both gravitational circulation and tide-driven dispersive fluxes were also important in transporting salt from 1 to $19 \mathrm{~km}$ during neap tide where $0.1<v<0.9$. Landward of $20 \mathrm{~km}$ gravitational circulation exchange was much more effective than tide-driven dispersion during spring and neap tides where $v<0.3$. MacCready (2004) found $v=0$ at the upstream end and $v \sim 0.8$ near the mouth of the Hudson River Estuary. The results of Savenije (1993), MacCready (2004) and Nguyen et al. (2008) are consistent with this calculation.

www.hydrol-earth-syst-sci.net/14/1465/2010/

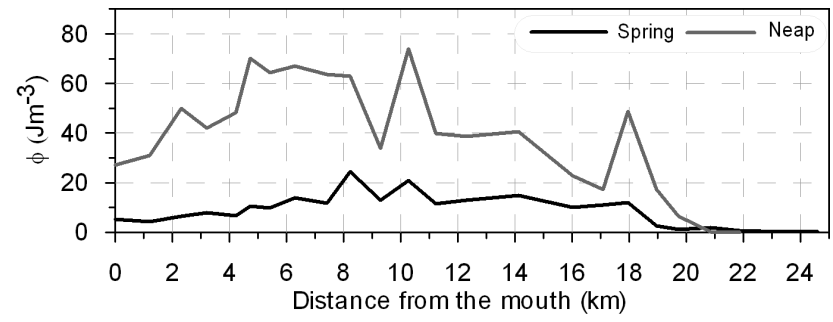

Fig. 12. Spatial variation in the potential energy anomaly during spring and neap tides along the Sumjin River Estuary. Each contour is the average of twelve samples obtained from August 2004 to April 2007.

\section{Discussion}

\subsection{Exchange processes based on potential energy anomaly}

The horizontal density gradient has important implications in generating tidally varying stratification and gravitational circulation (Savenije, 2005). Strong stratification events are periods of intense gravitational circulation (Monismith, 1996) which are linked through straining of the salinity field. Tidal straining is the result of velocity shear acting on a horizontal density gradient creating oscillations in the stratification of the water column (Murphy et al., 2009). To determine the influence of tidal straining on water column stratification, which is strongly linked with gravitational circulation, the potential energy anomaly $\phi$ of the water column for each CTD cast was calculated. Following the approaches of Simpson et al. (1990) and de Boer et al. (2008), the potential energy anomaly is the amount of work necessary to completely mix the water column $\left(\mathrm{Jm}^{-3}\right)$ which can be calculated from

$\phi=\frac{1}{H} \int_{-H}^{0} g z(\bar{\rho}-\rho) d z$

with the depth average density

$\bar{\rho}=\frac{1}{H} \int_{-H}^{0} \rho d z$

where $\rho$ is the vertical density profile over the water column of depth $H, z$ is the vertical coordinate and $g$ is the gravitational acceleration $\left(9.8 \mathrm{~ms}^{-2}\right)$. For a given density profile, $\phi$ $\left(\mathrm{Jm}^{-3}\right)$ represents the amount of work required to completely mix the water column.

Variations in the tidal exchange and gravitational circulation exchange naturally arise through neap-spring variations in the presence of the potential energy anomaly along the SRE. Figure 12 depicts the spatial variation in the potential energy anomaly $\phi$ during spring and neap tides along the SRE. Each contour of the spring and neap tides was the 
average for twelve samples obtained from August 2004 to April 2007. The strength of tide-driven mixing and stratification varied significantly between the spring and neap tides, up to approximately $20 \mathrm{~km}$ landward, as a function of $\phi$.

The amount of $\phi$ was less than $10 \mathrm{Jm}^{-3}$ during spring tide near the mouth (landward of $7 \mathrm{~km}$ ) of the SRE due to tidally driven turbulent mixing (Fig. 12). Burchard and Hofmeister (2008) have examined the dynamics of the potential energy anomaly at a location, where the water column is fully destabilized during flood, with a range of $\phi$ between 0 and $9 \mathrm{Jm}^{-3}$. Therefore, it can be assumed that tide-driven exchange may be dominant, when $\phi$ is $<10 \mathrm{Jm}^{-3}$. In addition, the tidal exchange zone extends roughly a tidal excursion from the mouth (Signell and Butman, 1992). The median tidal excursion observed in the SRE was $6.8 \mathrm{~km}$ (Shaha and Cho, 2009), that indicating the tidal exchange zone. Signell and Butman (1992) also found rapid exchange in the tidal mixing zone. As per the stratification parameter, well-mixed conditions were found near the mouth (landward about $7 \mathrm{~km}$ ) of the SRE during spring tide (Shaha and Cho, 2009), that also indicating the tidal exchange zone. Thus, the tidal exchange zone, as determined from the flushing rate near the mouth during spring tide, is consistent with the function of $\phi$, stratification parameter and tidal excursion.

In contrast, the amount of $\phi$ increased to $10 \sim 24 \mathrm{Jm}^{-3}$ during spring tide landward of $7 \mathrm{~km}$ from the mouth. The water column contained more $\phi$ in the central and inner regimes of the SRE relative to the mouth due to the reduction in mixing as the $\mathrm{M}_{2}$ tidal amplitude decreased by $12 \%$ within the estuary (Table 1). As a consequence, both gravitational circulation exchange and tide-driven exchange were important in transporting salt in the central and inner regimes of the SRE (landward of $7 \mathrm{~km}$ ) under various river discharge conditions.

Increased values of $\phi$ in the water column $(27<\phi<$ $67 \mathrm{Jm}^{-3}$ ) represents stronger stratification during neap tide than during spring tide. The weaker turbulence during a neap tide could lead to the reduction in mixing and the consequent increase of $\phi$ in the water column enhanced gravitational circulation. Both gravitational circulation exchange and tidedriven exchange were contributed in transporting salt into the SRE. Gravitational circulation exchange is not necessarily proportional to the potential energy anomaly in the water column. The dynamics of the potential energy anomaly has examined by Burchard and Hofmeister (2008) on a strongly stratified water column, where gravitational circulation exchange exists over the whole tidal period, with a range of $\phi$ between 45 and $60 \mathrm{Jm}^{-3}$. The link between stratification and gravitational circulation develops during neap tide due to the significant reduction in vertical mixing, which is the result of the weakened bottom friction (Nunes Vaz et al., 1989; Monismith et al., 1996).

There was no substantial amount of $\phi$ required to completely mix the water column landward of $20 \mathrm{~km}$, where gravitational circulation exchange was entirely dominant in transporting salt during spring and neap tides (Fig. 11). This
Table 3. chlorophyll- $a$ concentration in the Sumjin River Estuary (Park et al., 2005).

\begin{tabular}{lc}
\hline Station & chlorophyll- $a$ concentration $(\mu \mathrm{gL}-1)$ \\
\hline CTD23 & $2.5 \sim 18.2$ \\
CTD21 & $3.7 \sim 108.9$ \\
CTD15 & $3.0 \sim 44.4$ \\
CTD11 & $3.8 \sim 45.2$ \\
CTD8 & $2.5 \sim 48.5$ \\
CTD2 & $2.8 \sim 23.7$ \\
\hline
\end{tabular}

also indicates that the tidal effects decreased at landward of $20 \mathrm{~km}$ from the mouth, and the combined effects between tidal exchange and gravitational circulation exchange started from this location. Thus, the tidal exchange and gravitational circulation exchange, calculated using the flushing rate, showed consistency with the function of potential energy anomaly.

\subsection{Effects of exchange processes on spatial heterogene- ity of chlorophyll- $a$}

The flushing rate for the entire SRE could not provide information about the connections between the transport and spatial heterogeneity of non-conservative quantities such as chlorophyll- $a$. Conversely, the calculation of the flushing rate for multiple segments of the SRE provided strong clues about the importance of transport processes in shaping the spatial patterns of chlorophyll- $a$. Park et al. (2005) conducted a study on spatiotemporal fluctuations in the abundance of the demersal copepod, Pseudodiaptomus sp., in the SRE during spring tide. The chlorophyll- $a$ concentrations measured during their research period are shown in Table 3. The concentrations were lowest at upstream end where salt transport almost entirely by gravitational circulation (Shaha and Cho, 2009). As gravitational circulation exchange may increase in strength with increasing river flow, advective transport of estuarine resident populations will increase (Monismith et al., 2002). Owing to this advective loss, the chlorophyll- $a$ concentration was lowest at upstream end segment. However, the chlorophyll- $a$ concentration was highest at the distance of $20 \mathrm{~km}$ due to the advection by the river flow from upstream end. This region is the landward limit of haline stratification as a function of $\phi$ where there is no net landward and seaward movement of water. As a result, Pseudodiaptomus sp. maintained their positions in this region.

Conversely, lower concentration of chlorophyll- $a$ was also found near the mouth of the SRE during spring tide. Strong tide-driven exchange was found near the mouth during spring tide (Figs. 7, 9, 11 and 12), which caused advection of planktonic organisms from the mouth of the SRE to Gwangyang bay. As a result, the concentration was lower near the mouth. 
Hydrodynamic conditions, such as tide-driven exchange and gravitational circulation exchange, are entirely different during spring and neap tides in the SRE. Therefore, a study on the abundance of the demersal copepod, Pseudodiaptomus sp., should be conducted during neap tide, as the SRE is strongly stratified during neap tide that inhibits vertical migration of planktonic organisms.

\section{Conclusions}

Single flushing rate of the SRE did not show the spatial variation of exchange characteristics. To investigate spatial and spring-neap variations of gravitational circulation and tidedriven exchanges the flushing rate was calculated between multiple segments of the SRE and the adjacent bay. The tides caused rapid exchange in the vicinity of the mouth during spring tide compared to neap tide. The stratification and water column stability was found to vary in different sections of the SRE as a function of potential energy anomaly which modulated gravitational circulation and tide-driven exchanges.

The tide-driven dispersion was dominant at low river discharge condition along the SRE during spring and neap tides. Tide-driven dispersive flux of salt was also dominant near the mouth (landward of $7 \mathrm{~km}$ ) during spring tide for all river discharge conditions observed due to the larger tidal amplitude where gravitational circulation ceased. However, both gravitational circulation and tidal exchanges were contributed in transporting salt in the central and inner regime during spring tide due to the reduction in tidal amplitude that caused partially stratified conditions. The combined contributions of two fluxes were also appeared during neap tide along the SRE. Gravitational circulation exchange entirely dominated for salt flux at the upstream end during spring and neap tides.

These results furnished strong clues about the spatially varying abundance of planktonic organisms in the SRE. Results suggested the use of spatially varying flushing rate to estimate tide-driven and gravitational circulation exchanges, and also to understand the distributions of living biomass and suspended particles in an estuary.

Acknowledgements. This research was supported by the NAP program of the Korea Ocean Research Development Institute and the project titled "Dynamics and prediction of long-term ocean climate variability" funded by MLTM. The helpful comments of H. H. G. Savenije, an anonymous reviewer and P. A. G. Regnier substantially improved this manuscript. The authors would like to acknowledge the members of the Earth Environment Prediction Laboratory for their enthusiastic supports during the data collection.

Edited by: P. Regnier

\section{References}

Bae, D. H., Jung, I. W., and Chang, H.: Long-term trend of precipitation and runoff in Korean river basins, Hydrol. Process., 22 2644-2656, 2008.

Bell, C., Vassie, J. M., and Woodworth, P. L.: POL/PSMSL Tidal Analysis Software Kit 2000 (Task-2000), Permanent Service for Mean Sea Level, CCMS Proudman Oceanographic Laboratory, Bidston Observatory, Birkenhead, UK, 20 pp., 1999.

Bowden, K. F. and Gilligan, R. M.: Characteristic feature of estuarine circulation as represented in the Mersey estuary, Limnol. Oceanogr., 16, 490-502, 1971.

Burchard, H. and Hofmeister, R.: A dynamic equation for the potential energy anomaly for analysing mixing and stratification in estuaries and coastal seas, Estuar. Coast. Shelf S., 77, 679-687, 2008.

de Boer, G. J., Pietrzak, J. D., and Winterwerp, J. C.: Using the potential energy anomaly equation to investigate tidal straining and advection of stratification in a region of freshwater influence, Ocean Model., 22, 1-11, 2008.

deCastro, M., Gomez-Gesteira, M., Prego, R., and Alvarez, I.: Riaocean exchange driven by tides in the Ria of Ferrol (NW Spain), Estuar. Coast. Shelf S., 61, 15-24, 2004.

Dyer, K. R.: Estuaries, A Physical Introduction, John Wiley, London, UK, 2nd Edn., 195 pp., 1997.

Fram, J. P., Martin, M. A., and Stacey, M. T.: Dispersive fluxes between the Coastal Ocean and a semienclosed estuarine Basin, J. Phys. Oceanogr., 37, 1645-1660, doi:10.1175/JPO3078.1, 2007.

Geyer, W. R.: The importance of suppression of turbulence by stratification on the estuarine turbidity maximum, Estuaries, 16, 113 125,1993

Gordon, D. C., Boudreau, P. R., Mann, K. H., Ong, J.-E., Silvert, W. L., Smith, S. V., Wattayakorn, G., Wulff, F., and Yanagi, T. LOICZ Biogeochemical Modelling Guidelines, LOICZ Reports \& Studies No 5, 1-96, 1996.

Hansen, D. V. and Rattray, R.: New dimensions in estuary classification, Limnol. Oceanogr., 11, 319-326, 1966.

Hansen, D. V. and Rattray, R.: Gravitational circulation in straits and estuaries, J. Mar. Res., 23, 104-122, 1965.

Hough, A. R. and Naylor, E.: Field studies on retention of the planktonic copepod Eurytemora affinis in a mixed estuary, Mar. Ecol. Prog. Ser., 76, 115-122, 1991.

Jassby, A. D., Kimmerer, W. J., Monismith, S. G., Armor, C., Cloern, J. E., Powell, T. M., Schubel, J. R., and Vendlinski, T. J.: Isohaline position as a habitat indicator for estuarine populations, Ecol. Appl., 5, 272-289, 1995.

Jay, D. A. and Smith, J. D.: Circulation, density structure and neap-spring transitions in the Columbia River Estuary, Prog. Oceanogr., 25, 81-112, 1990.

Ji, Z. G.: Hydrodynamics and Water Quality: Modeling Rivers, Lakes and Estuaries, John Wiley, New Jersey, USA, 1st Edn., 676 pp., 2008.

Kimmerer, W. J., Burau, J. R., and Bennett, W. A.: Persistance of tidally-oriented vertical migration by zooplankton in a temperate estuary, Estuaries, 25, 359-371, 2002.

Kimmerer, W. J., Burau, J. R., and Bennett, W. A.: Tidally oriented vertical migration and position maintenance of zooplankton in a temperate estuary, Limnol. Oceanogr., 43, 1697-1709, 1998.

MacCready, P.: Toward a unified theory of tidally-averaged estuarine salinity structure, Estuaries, 27, 561-570, 2004. 
McCarthy, R. K.: Residual currents in tidally dominated, wellmixed estuaries, Tellus, 45A, 325-340, 1993.

Monismith, S. G., Burau, S. R., and Stacey, M.: Stratification dynamics and gravitational circulation in northern San Francisco Bay, in: San Francisco Bay: The Ecosystem, edited by: Hollibaugh, J. T., American Association for the Advancement of Science, San Francisco, California, 123-153, 1996.

Monismith, S. G., Kimmerer, W., Stacey, M. T., and Burau, J. R.: Structure and flow-induced variability of the subtidal salinity field in Northern San Francisco Bay, J. Phys. Ocean., 32, $3003-$ 3019, 2002.

Monsen, N. E, Cloern, J. E., Lucas, L. V., and Monismith, S. G.: A comment on the use of flushing time, residence time, and age as transport time scales, Limnol. Oceanogr., 47, 1545-1553, 2002.

Morgan, C. A., Cordell, J. R., and Simenstad, C. A.: Sink or swim? Copepod population maintenance in the Columbia River estuarine turbidity-maxima region, Mar. Biol., 129, 309-317, 1997.

Murphy, P., Waterhouse, A., Hesser, T., Penko, A., and ValleLevinson, A.: Subtidal flow and its variability at the entrance to a subtropical lagoon, Cont. Shelf Res., 29, 2318-2332, 2009.

Nguyen, A. D., Savenije, H. H. G., van der Wegen, M., and Roelvink, D.: New analytical equation for dispersion in estuaries with a distinct ebb-flood channel system, Estuar. Coast. Shelf S, 79, 7-16, doi:10.1016/j.ecss.2008.03.002, 2008.

Nunes Vaz, R. A., Lennon, G. W., and de Silva Samarasinghe, J. R.: The negative role of turbulence in estuarine mass transport, Estuar. Coast. Shelf S., 28, 361-377, 1989.

Officer, C. B. and Kester, D. R.: On estimating the non-advective tidal exchanges and advective gravitational circulation exchanges in an estuary, Estuar. Coast. Shelf S., 32, 99-103, 1991.

Park, E. O., Suh, H. L., and Soh, H. Y.: Seasonal variation of the abundance of the demersal copepod Pseudodiaptomus sp., (Calanoida, Pseudodiaptomidae) in the Seomjin River Estuary, South Korea, Korean J. Environ. Biol., 23, 367-373, 2005.

Pilson, M. E. Q.: On the residence time of water in Narragansett bay, Estuaries, 8, 2-14, 1985.

Regnier, P., Mouchet, A., Wollast, R., and Ronday, F.: A discussion of methods for estimating residual fluxes in strong tidal estuaries, Cont. Shelf Res., 18, 1543-1571, 1998.
Ribeiro, C. H. A., Waniek, J. J., and Sharples, J.: Observations of the spring-neap modulation of the gravitational circulation in a partially mixed estuary, Ocean Dyn., 54, 299-306, 2004.

Savenije, H. H. G.: Composition and driving mechanisms of longitudinal tidal average salinity dispersion in estuaries, J. Hydrol., 144, 127-141, 1993.

Savenije, H. H. G.: Salinity and Tides in Alluvial Estuaries, 1st Edn., Elsevier, Amsterdam, The Netherlands, 197 pp., 2005.

Shaha, D. C. and Cho, Y.-K.: Comparison of empirical models with intensively observed data for prediction of salt intrusion in the Sumjin River estuary, Korea, Hydrol. Earth Syst. Sci., 13, 923 933, doi:10.5194/hess-13-923-2009, 2009.

Signell, R. P. and Butman, B.: Modeling tidal exchange and dispersion in Boston Harbor, J. Geophys. Res., 97, 15591-15606, 1992.

Simpson, J. H., Brown, J., Matthews, J., and Allen, G.: Tidal straining, density currents and stirring control of estuarine circulation, Estuaries, 13, 125-132, 1990.

Smith, S. V. and Hollibaugh, J. T.: Water, salt, and nutrient exchange in San Francisco Bay, Limnol. Oceanogr., 51, 504-517, 2006.

Uncles, R. J. and Stephens, J. A.: Salt intrusion in the Tweed Estuary, Estuar. Coast. Shelf S., 43, 271-293, 1996.

Uncles, R. J., Elliott, R. C. A., and Weston, S. A.: Observed fluxes of water, salt and suspended sediment in a partially mixed estuary, Estuar. Coast. Shelf S., 20, 147-167, 1985.

Valle-Levinson, A.: Contemporary Issues in Estuarine Physics, 1st Edn., Cambridge University Press, Cambridge, UK, 326 pp., 2010.

West, J. R. and Broyd, T. W.: Dispersion coefficients in estuaries, Proceedings of the Institution of Civil Engineers, 71, 721-737, 1981.

Yanagi, T. and Abe, R.: Increase in water exchange ratio due to a decrease in tidal amplitude in Ariake Bay, Japan, Cont. Shelf Res., 25, 2174-2181, 2005. 